\title{
Correction to: Screening and selection of accessions in the genus Pisum L. for resistance to pulse beetle (Callosobruchus chinensis L.)
}

\author{
Azime Esen - Hatice Sari (1) - Fedai Erler (1) - Alper Adak (i) Duygu Sari $($ ) \\ Tuba Eker (D) Huseyin Canci - Cengiz İkten (D) Abdullah Kahraman • \\ Cengiz Toker
}

Published online: 9 September 2019

(C) Springer Nature B.V. 2019

\section{Correction to: Euphytica (2019) 215:82 https://doi.org/10.1007/s10681-019- 2395-4}

With respect to ACP 100 germplasm, we have been notified by Dr. S. Abbo (who provided the seeds) that the identification of this accession was mistaken. The identification does not conform to the morphological definitions of $P$. abyssinicum (Kosterin 2017), and therefore, ACP 100 should be considered as a traditional landrace of $P$. sativum.

Because of the above the following parts of the article have been corrected accordingly and should be regarded as final by the reader.

The original article can be found online at https:// doi.org/10.1007/s10681-019-2395-4.

A. Esen · H. Sari · A. Adak · D. Sari - T. Eker .

H. Canci · C. Toker $(\bowtie)$

Department of Field Crops, Faculty of Agriculture,

Akdeniz University, Antalya, Turkey

e-mail: toker@akdeniz.edu.tr

F. Erler $\cdot$ C. İkten $(\bowtie)$

Department of Plant Protection, Faculty of Agriculture,

Akdeniz University, Antalya, Turkey

e-mail: cikten@akdeniz.edu.tr

\section{A. Kahraman}

Department of Field Crops, Faculty of Agriculture, Harran

University, Sanliurfa, Turkey

\begin{abstract}
The use of resistant plant varieties is an important control option in the management of seed beetles (Coleoptera: Bruchidae) under storage conditions. Therefore, the aim of the present study was to screen and select pea (Pisum L.) accessions for resistance to pulse beetle (Callosobruchus chinensis L.) under storage conditions. Seeds of three Pisum taxa including two accessions of $P$. sativum L. (ACP 11, ACP 15) and ACP 100, two accessions each of $P$. elatius M. Bieb. (AWP 442, AWP 449) and P. fulvum Sibth. \& Sm. (AWP 600, AWP 601) were evaluated using both free-choice and no-choice test methods for the pest under laboratory conditions. Resistance was evaluated by measuring number of eggs per seed by the bruchid (oviposition), number of holes per seed (adult emergence), percent of seed damage and seed weight loss (\%). Both accessions of P. fulvum (AWP600, AWP 601) and one accession each of $P$. elatius (AWP 442) and P. sativum (ACP 11) had no emergence holes and seed weight loss in both tests. Overall, the results suggest that the $P$. sativum accession, ACP 11, may be used to sustain the damage caused by the pulse beetle without using pesticides during the storage. Additionally, the accessions of wild species ( $P$. elatius-AWP 442 and $P$. fulvumAWP 600, AWP 601) that were identified as completely resistant could be used in breeding programs for the improvement of resistant cultivars.
\end{abstract}


Table 1 Specific characteristics of seeds among Pisum taxa

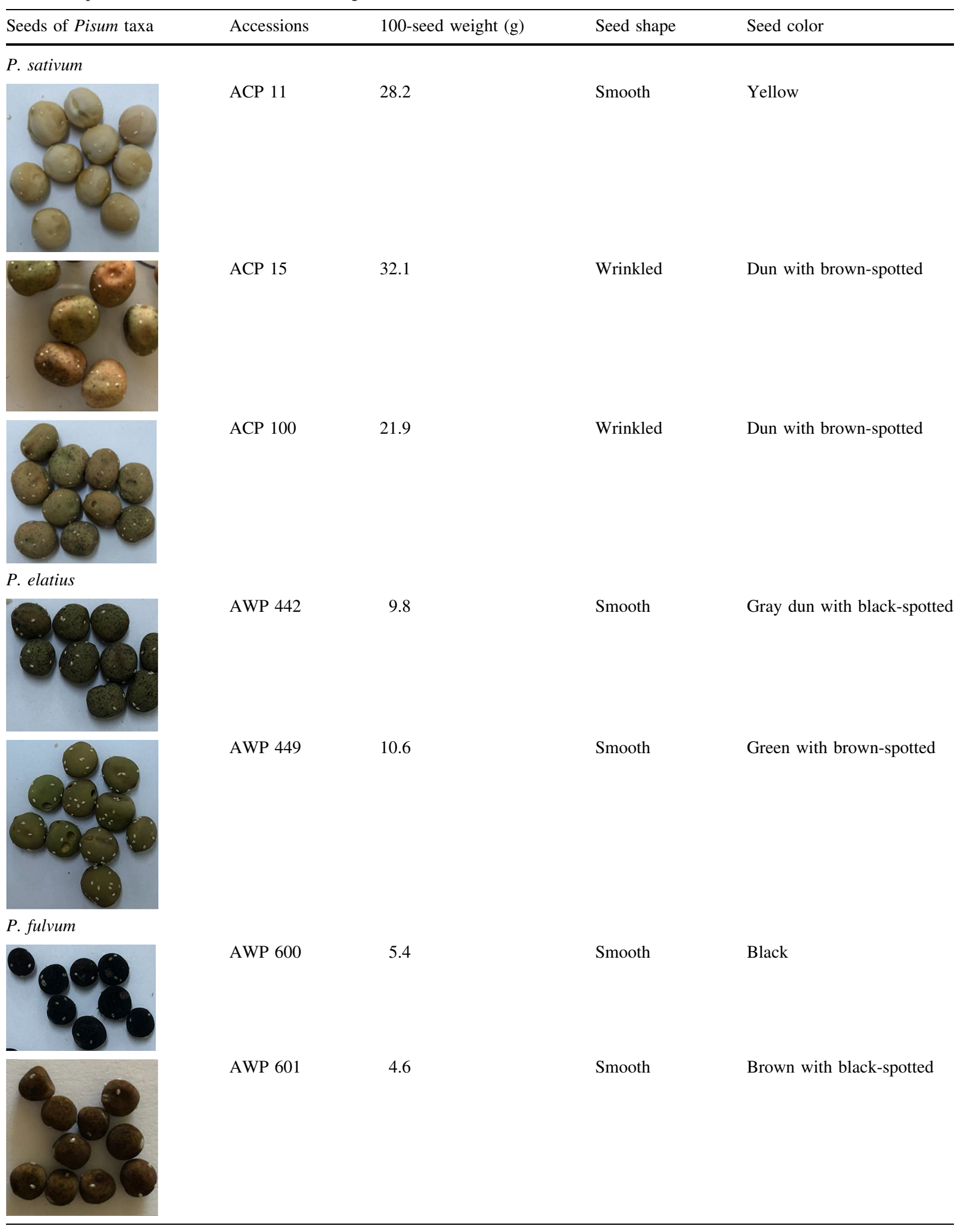


Hence, the aim of the present study was to evaluate different pea accessions of $P$. sativum, P. elatius and $P$. fulvum for resistance to $C$. chinensis.

\section{Materials and methods}

\section{Pisum taxa}

In the present study, seeds of three Pisum taxa, three accessions of $P$. sativum L. (ACP 11, ACP 15 and ACP 100), two accessions of $P$. elatius (AWP 442 and AWP 449) and two accessions of $P$. fulvum (AWP 600 and AWP 601) were evaluated for resistance to $C$. chinensis using both free-choice and no-choice test methods under laboratory conditions.

Acknowledgements The current study was the Master Science thesis of the first author (AE). CT as adviser and CI as miner adviser thank Scientific Research Project Coordination Unit of Akdeniz University for financial support (FYL-2017-
2123). Accessions belong to the project (1190060) financed by TUBITAK. Thanks are given to Professor Shahal Abbo from The Hebrew University of Jerusalem, Israel for supplying the $P$. sativum (ACP 100) in the study. Also, special thanks are given to anonymous reviewer for additional valuable comments.

\section{Reference}

Kosterin OE (2017) Abyssinian pea (Lathyrus schaeferi Kosterin nom. nov. pro Pisum abyssinicum A. Br.) is a problematic taxon. Vavilovskii Zhurnal Genetiki i Selektsii = Vavilov J Genet Breed 21(2):158-169. https:// doi.org/10.18699/vj17.234

Publisher's Note Springer Nature remains neutral with regard to jurisdictional claims in published maps and institutional affiliations. 